\section{O escritor sobrevivente: uma questão de visibilidade}

\section{The survivor writer: a matter of visibility}

\author{
Vivian Resende Jatobá ${ }^{[a]}$, \\ Sérgio Araújo de Sá ${ }^{[b]}$
}

\section{Resumo}

O escritor, dedicado a obras nas quais pretende lançar seu olhar mais reflexivo e cuidadoso sobre as angústias humanas, depara-se com certas dificuldades que dizem respeito à falta de visibilidade de seus livros. Para alcançar tal visibilidade, entretanto, ele se submete às exigências de um mercado editorial que privilegia uma literatura de mais fácil compreensão, e que deseja alcançar um público leitor mais amplo, o qual não se dê ao trabalho de fazer reflexões profundas. Nesse cenário, o escritor, motivado por necessidade financeira, se vê obrigado a ceder, renunciando às suas convicções e fazendo algo contra a [a] Mestranda do Programa de PósGraduação em Comunicação da Universidade Nacional de Brasília (UnB), graduada em Letras com habilitação em Língua Portuguesa (UnB), Brasília, DF - Brasil, e-mail: vivian.resende@gmail.com

[b] Doutor em Estudos Literários pela Universidade Federal de Minas Gerais (UFMG), professor da Faculdade de Comunicação da Universidade Nacional de Brasília (UnB), jornalista e crítico literário, Brasília, DF - Brasil.

Palavras-chave: Escritor. Obra. Cultura da mídia. Visibilidade. 
própria vontade a fim de dar à sua obra alguma visibilidade e a si mesmo um retorno financeiro. Como ele, outros artistas se veem na mesma situação, e suas opções são fracassar por meio da renúncia ao dinheiro ou às suas próprias convicções. Clarice Lispector e Sidney Orr são exemplos dessa situação, embora a primeira se situe no plano da realidade e o segundo seja um personagem ficcional de Paul Auster. Este artigo se propõe, assim, a explorar o drama vivido por eles para ilustrar o fenômeno analisado.

\section{Abstract}

The writer, who is dedicated to compositions which intend to cast a rather reflexive and careful outlook about the human suffering, faces certain difficulties with regards to the lack of visibility of his books. To achieve such visibility, however, he vails to the demands of a publishing market that privileges literature of an easier understanding and wishes to reach a wider readership that does not bother to do deep thinking. In such scenario, the writer, who is motivated by financial needs, is obliged to give over, renouncing his convictions and doing something against his will in order to give some visibility to his work and a financial return for himself. Like him, other artists find themselves in the same situation, and their option is the failure by renouncing the money or their own convictions. Clarice Lispector and Sidney Orr are examples of such situation, although the first is located in the plane of reality and the second is a fictional character created by Paul Auster. This article therefore proposes to explore their drama to illustrate the phenomenon analyzed.

Este trabalho trata da relação entre literatura e media por meio da figura do escritor e de sua visibilidade, adquirida em decorrência da sua obra. Mais precisamente, analisaremos a presença de Clarice Lispector no Jornal do Brasil, no qual publicou crônicas de 1967 a 1973, e faremos uma comparação com a personagem Sidney Orr, do romance Noite do 
Oráculo, de Paul Auster, obra lançada em 2003. Distantes temporal e geograficamente, a Lispector real e o Orr inventado sinalizam aspectos similares que dizem respeito a quem escreve e sua inserção no mercado editorial e na mídia, que lhes exigem posturas para vendagem e circulação da obra. Em que medida personagem e pessoa se confundem?

Clarice Lispector preferia não escrever para o jornal. Sentia-se desconfortável por ter que assumir o próprio rosto e negar o direito à máscara que a ficção permitia usar. Entretanto, não tinha alternativa e teve de fazê-lo, assinando uma coluna semanal e colocando-se ao alcance de uma amostra maior de leitores. O terreno ficcional lhe rendera reconhecimento, mesmo sendo a escrita de Clarice Lispector geradora do velho e bom estranhamento. O texto da prosa de ficção não é o que se pode chamar de best-seller: não se trata de enredo de propulsão curiosa, destinado a empurrar o leitor páginas adentro como se em uma corrida sem barreiras. Clarice, sabe-se, instiga de outro modo. Ela propõe questionamentos, reflexões abaixo e acima da superfície, a partir de epifanias, de episódios que se ressignificam e tornam sublime o que parecia banal.

Em Água viva, ela diz:

Quero escrever-te como quem aprende. Fotografo cada instante. Aprofundo as palavras como se pintasse, mais do que um objeto, a sua sombra. Não quero perguntar por que, pode-se perguntar sempre por que e sempre continuar sem resposta: será que consigo me entregar ao expectante silêncio que se segue a uma pergunta sem resposta? Embora adivinhe que em algum lugar ou em algum tempo existe a grande resposta para mim (LISPECTOR, 1998, p. 14).

Os instantes fotografados são captados pelo olhar de Clarice de ângulos bastante subjetivos, que aprofundam reflexões e demandam diálogo mais rigoroso, de modo que se exige, portanto, um leitor mais interessado, mais disposto a navegar na leitura mesmo à custa da ultrapassagem de alguns obstáculos. Essa leitura é distinta daquela que o mercado privilegia.

Ao falarmos das preferências do mercado, somos levados a explorar as especificidades da cultura da mídia, que, de acordo com Douglas Kellner,

[...] define o que é considerado bom ou mau, positivo ou negativo, moral ou imoral. As narrativas veiculadas pela mídia fornecem os símbolos, os mitos e os recursos que ajudam a constituir uma cultura comum para a maioria dos indivíduos em muitas regiões do mundo de hoje. A cultura 
veiculada pela mídia fornece o material que cria as identidades pelas quais os indivíduos se inserem nas sociedades tecnocapitalistas e contemporâneas, produzindo uma nova forma de cultura global (2001, p. 9).

Isto é, se as identidades dos indivíduos inseridos nas sociedades contemporâneas são criadas pela mídia, o escritor, caso deseje tornar sua obra visível, deveria ingressar nesse mercado à custa da venda de sua imagem, o que pode implicar algumas renúncias, como tiveram que fazer Sidney Orr, na ficção, e Clarice Lispector, fora dela. Isso porque "trata-se de uma cultura da imagem, que explora a visão e a audição" (2001, p. 9). Kellner aponta ainda que:

A cultura da mídia é industrial; organiza-se com base no modelo de produção de massa e é produzida para a massa de acordo com tipos (gêneros), segundo fórmulas, códigos e normas convencionais. É, portanto, uma forma de cultura comercial, e seus produtos são mercadorias que tentam atrair o lucro privado produzido por empresas gigantescas que estão interessadas na acumulação de capital (2001, p. 9).

Dessa maneira, uma cultura que prioriza a obtenção do lucro prioriza também a produção de objetos para rápido consumo. É nesse contexto que cabe discutirmos a literatura e o papel do escritor, que se divide entre o dilema de escrever atendendo à demanda midiática e obtendo visibilidade e retorno financeiro, ou de escrever de acordo com sua vontade de gerar reflexão, mas correndo o risco de não ser reconhecido por estar fora do circuito midiático.

Sérgio de Sá resume bem esse cenário:

Se a mídia é a instituição hegemônica por excelência, qualquer alinhamento às suas premissas significa abrir mão da vontade particular para submeter-se a valores mercadologicamente válidos [...]. Assim, o que diferencia a arte (a literatura) é que ela não produz temas que os meios possam transformar facilmente em informação: desde o tempo necessário para a leitura de uma obra aos impedimentos linguísticos no approach do texto. Assim também ocorre com o intelectual participante, indisposto ao consenso. Já o autor recordista se alimenta do próprio sistema informacional. Ele é informação mediática (2010, p. 35, grifo do autor). 
Entre uma literatura e outra, cabe a distinção que Silviano Santiago emprega para diferenciar espetáculo de simulacro: "O primeiro leva à reflexão e o outro serve para matar o tempo" (2004b, p. 126). Isto é, uma literatura como a de Clarice Lispector, que gera essa reflexão, assemelha-se ao espetáculo, definido por Santiago como "manifestação legítima da cultura" (2004b, p. 125), enquanto a dos best-sellers equivaleria ao simulacro, um "entretenimento da indústria cultural” (2004b, p. 125), que não pretende mais do que preencher o tempo do receptor sem precisar fazê-lo refletir.

O mercado editorial, inserido na cultura da mídia, interessa-se mais pelo potencial de uma literatura com alto poder de vendagem. No cenário em que a cultura de massa absorve a majoritária atenção dos indivíduos, o produto que se incorpora nesse meio sem meios termos é bem-vindo, com o perdão da redundância (ela é aceita com naturalidade). Assim, escritores com pretensão de verdadeiramente aprofundar angústias humanas, mas pouco animados a fazer concessões, perdem lugar. A concorrência é desigual. A obra que não serve apenas para preencher o tempo do leitor é obrigada a abrir brechas na posteridade.

Para a argentina Beatriz Sarlo, há mesmo a "literatura de qualidade", que até pode não se apresentar como mercantil, mas apenas imita a boa literatura, sem inovações, simplesmente construindo "simulacros cultos". Nunca é "esteticamente interessante", apesar de cumprir uma "função respeitável". Diz Sarlo: "Sua especialidade são as formas já provadas como eficazes, incluindo os procedimentos da boa literatura" (2012, p. 15). Haveria uma novidade temática aprendida, ou apreendida, do best-seller.

O interesse do leitor comum caminha, portanto, na direção do fruir o tempo menos com reflexão e mais com entretenimento. Nesse sentido, o escritor, para sobreviver, deve se reinventar, submetendo-se às exigências de um mercado que pretende satisfazer o consumidor - pois é assim que interessa perceber o leitor.

Novamente recorremos a Sérgio de Sá. Ele diz que

[...] a literatura está dentro de uma esfera pública [...] onde se sobressai a vontade do mercado, que privilegia o entretenimento. 0 espaço público tomado pela teatralização mediática é a tela sobre a qual os produtores de textos literários se veem e sobre a qual devem construir seu discurso, sua reputação (2010, p. 20). 
Não nos restam dúvidas de que a prioridade do mercado editorial, boa parte das vezes, diverge dos interesses do escritor. Aqui, nossos exemplos são Clarice Lispector, na realidade, e Sidney Orr, na ficção, mas Sérgio Sant'Anna é lembrado por Sérgio de Sá: "o escritor também tem que se contrapor à mídia, não se deixar seduzir pelo que é fácil" (SANT'ANNA, 1995 apud SÁ, 2010, p. 20). Entretanto, à medida que se contrapõe à mídia, o escritor renuncia à visibilidade de si mesmo e de sua obra. Em decorrência disso, naturalmente, ele deixa de ganhar dinheiro.

É considerando esse dilema que o escritor deve se reinventar, cedendo aqui e ali para que suas escolhas não impliquem ostracismo, uma vez que "[Os espetáculos da mídia] dramatizam e legitimam o poder das forças vigentes e mostram aos não poderosos que, se não se conformarem, estarão expostos ao risco de prisão ou morte" (KELLNER, 2001, p. 10). Assim, ao escritor cabe a escolha de se conformar ou não, assumindo os riscos de sua opção.

O público tem curiosidade pela figura do escritor. Não por acaso, biografias parecem atraentes. Alguns escritores, entretanto, são avessos à exposição e vem daí o temor de Clarice Lispector quando não Ihe restava alternativa senão, por necessidade financeira, aderir à crônica, gênero pessoal, que contribuía para a sua exposição, pois se trata de um hibridismo que faz dialogar a literatura e a realidade. Quando assume a função de cronista, então, ela se desconcerta:

Ainda continuo um pouco sem jeito na minha nova função daquilo que não se pode chamar propriamente de crônica. E, além de ser neófita no assunto, também o sou em matéria de escrever para ganhar dinheiro. Já trabalhei na imprensa como profissional, sem assinar. Assinando, porém, fico automaticamente mais pessoal. E sinto-me um pouco como se estivesse vendendo minha alma (LISPECTOR, 1999, p. 29).

Ao escrever para o jornal, Clarice "vende sua alma", ficando mais pessoal e deixando histórias do cotidiano ao alcance do leitor, a quem interessa conhecer a figura do escritor. Dessa maneira, Clarice Lispector precisa da visibilidade midiática para se sustentar.

Sou uma colunista feliz. Escrevi nove livros que fizeram muitas pessoas me amar de longe. Mas ser cronista tem um mistério que não entendo: é que os cronistas, pelo menos os do Rio, são muito amados. E escrever a espécie de crônica aos sábados tem me trazido mais amor ainda. 
Sinto-me tão perto de quem me lê. E feliz por escrever para os jornais que me infundem respeito (LISPECTOR, 1999, p. 95).

O gênero desconcertante possibilita a proximidade entre autor e leitor, uma vez que este encontra o texto no espaço do jornal, que pertence à sua rotina. E como são textos de fácil compreensão, o autor se torna tão acessível quanto pessoal. No caso de Clarice, a quem incomodava ter que se dar a conhecer por meio de relatos pessoais, que revelavam sobre sua vida, o que justifica a presença no jornal é a necessidade financeira, como acontece a tantos escritores que têm de abdicar de suas convicções pelo mesmo motivo. Em alguns de seus textos, isso fica claro:

Tantos querem a projeção. Sem saber como esta limita a vida. Minha pequena projeção fere o meu pudor. Inclusive o que eu queria dizer já não posso mais. $\mathrm{O}$ anonimato é suave como um sonho. Eu estou precisando desse sonho. Aliás eu não queria mais escrever. Escrevo agora porque estou precisando de dinheiro. Eu queria ficar calada. Há coisas que nunca escrevi, e morrerei sem tê-las escrito. Essas por dinheiro nenhum. Há um grande silêncio dentro de mim. E esse silêncio tem sido a fonte de minhas palavras. E do silêncio tem vindo o que é mais precioso que tudo: o próprio silêncio (LISPECTOR, 1999, p. 75-76).

A escritora tenta filtrar suas palavras na tentativa de impedir que tudo seja dito. Seu desejo é, apesar de não poder se recusar a escrever, ainda conservar de algum modo sua privacidade. Se pudesse, evitaria a projeção, que fere o pudor de que ela é obrigada a se despir, ainda que em parte. Clarice Lispector conserva algum silêncio e, mesmo nas crônicas - de pessoalidade inevitável - , ela pretende se preservar de alguma forma. A escritora, contudo, não pode se negar a escrever porque a visibilidade por meio do jornal é o modo como ela ganha dinheiro.

A mesma Clarice Lispector das crônicas é a que, em entrevista a Júlio Lerner, disse que o papel do escritor é "falar cada vez menos". Esse papel, entretanto, se choca com o que temos visto: um cenário no qual negar a visibilidade é negar também, na maioria das vezes, a possibilidade de se sustentar financeiramente. Como lembra Sérgio de Sá, a opção de falar cada vez menos "pode ser alternativa interessante ao falar excessivo da sociedade de informação. Mas como isso se apresenta à tentativa de visibilidade do intelectual (público), uma vez que a atuação na mídia é tão ou mais relevante do que a atuação no texto?" (2010, p. 22). Manter-se em silêncio e/ou renunciar às câmeras e/ou à exposição 
pode sair caro tanto para o escritor quanto para sua obra, por estarem afastados da visibilidade.

Diante de uma situação como essa, é inevitável refletir acerca da relação entre literatura e media, que exige do escritor certas concessões. Na sua atuação nos meios de comunicação (ainda de massa), deve-se considerar o que interessa ao público médio, constituído de leitores menos ou mais instruídos. A desigualdade na recepção configura território sem mapa preciso.

Aqui damos um salto para entrar na Noite do oráculo, romance do norte-americano Paul Auster (1947), lançado nos Estados Unidos em 2003. O protagonista é Sidney Orr, escritor que sai do hospital depois de quatro meses de internação. A personagem precisa pagar uma dívida de US\$ 36 mil, o que a motiva a escrever. Mais de 30 anos depois, a necessidade da personagem equivale à de Clarice Lispector e a de tantos outros escritores que vivem semelhante realidade. A ficção aproxima-se do real - e vice-versa - em mercados distantes, mas não tão distintos como se poderia imaginar.

Sidney, em uma de suas breves caminhadas pelo Brooklyn, em Nova York, quando ainda se recuperava depois da internação, depara-se com uma papelaria, cujo dono é o chinês Chang. Os negócios iam "muito devagar", com "muita desilusão" e representavam o "grande sonho americano" de Chang. Para ele, "o problema dos escritores é que a maioria não tem muito dinheiro para gastar" (AUSTER, 2004, p. 13), de modo que, se a papelaria não vai bem, tal fato deriva do fracasso dos escritores, que também não têm dinheiro.

Um ponto relevante para discussão é a noção bipolar de fracasso/ sucesso, tratada de modo mais aberto no universo norte-americano (o loser, o perdedor, é tema recorrente na ficção). Em Noite do oráculo, diz-se, em uma das notas de rodapé que margeiam o romance, que "van Velde é... o primeiro a admitir que ser artista é fracassar, como ninguém mais ousa fracassar, o fracasso é o seu mundo" (AUSTER, 2004, p. 168). Dessa maneira, aquele que faz sucesso, então, não seria artista? Se a arte suscita reflexões mais profundas, ressignificações de experiências e narrativas, ela não seria contemplada por uma lógica de mercado que privilegia o mais fácil em virtude da possibilidade de alcançar um público maior, mais afeito à imagem simulacro. A esse respeito, falaremos mais adiante, a fim de não separarmos completamente, de um lado, a arte e, de outro, a mídia. Sabe-se que, de algum modo, embora com certa dificuldade, ambas podem conviver sem se anular. 
Sidney Orr, na busca por dinheiro, tenta abrir mão das pretensões artísticas. Ele acata a ideia de escrever roteiro para cinema, embora saiba que, para que o projeto seja aceito, deve consistir em uma ideia estúpida, pouco "cerebral": "'Sei que é idiota', eu disse, 'mas, se eles comprarem a ideia, vamos poder pagar nossas contas de novo. Se não, continuamos no vermelho. Detesto ter de contar com projetos assim ralos, mas esse é o único truque que tenho na manga'” (AUSTER, 2004, p. 156).

Orr não consegue que seu projeto seja aceito: "disseram que a trama era muito cerebral" (AUSTER, 2004, p. 176), afinal, para um roteiro de Hollywood, deseja-se menos apelo ao que é cerebral, menos necessidade de reflexão e mais possibilidade de fruição sem esforço. Sidney Orr assemelha-se, assim, em alguma medida, a Clarice Lispector, se fizermos as devidas aproximações entre suas posturas, entre a crônica e o roteiro, entre a personagem-escritor inventada e a escritora que se reinventa na mídia. Por motivos e necessidade financeiros, os dois apelam para a escrita de gêneros dos quais não gostam ou com os quais não se identificam. Desse modo, ambos "se vendem" para o mercado, ou tentam se vender, abrindo mão de convicções em prol da subsistência. Por um lado, Clarice se despe de seu pudor e, por outro, Sidney se obriga a aderir a "projetos ralos".

Nisso consiste o fracasso: a necessidade de vender implica algumas renúncias, de modo que, no plano real, Clarice passa a assinar com o próprio nome no jornal e Sidney Orr, no ficcional, tenta ser menos "difícil". Clarice negocia a intimidade enquanto Orr cede e tenta fugir do que seria experimental demais. Afinal, dupla derrota: convicções são abandonadas, a formalidade da arte se despede do cotidiano para que sobressaia a necessidade financeira. Time is money, and money talks. 0 crédito póstumo dá lugar à grana do presente.

Nas palavras de Douglas Kellner, "o rádio, a televisão, o cinema e os outros produtos da indústria cultural fornecem os modelos daquilo que significa ser homem ou mulher, bem-sucedido ou fracassado, poderoso ou impotente" (2001, p. 9). Isto é, não se pode negar que o fracasso e/ ou sucesso de alguém passaram a ser determinados por produtos midiáticos. É por essa razão que, ao menos para sobreviver financeiramente, escritores da realidade e da ficção se veem obrigados a produzir não o que lhes agrada, mas o que a mídia exige. Afinal, é preciso se manter, de algum modo, sob os holofotes, pois, segundo Sá,

quando não há livro a ser lançado e, assim, baixo valor-notícia nos fatos relacionados à vida e à obra do escritor, ele acaba, salvo raras exceções, relegado 
ao limbo, ao desaparecimento, ao silêncio forçado. Porque escritores brasileiros já não são mais chamados a opinar, por exemplo, sobre a realidade nacional ou mundial. Estão ausentes. Daí advém a necessidade de produzir mais, para manter-se em cena, no foco das atenções (2010, p. 20-21).

Manter-se em silêncio, ainda que seja a vontade de alguns escritores, não os ajuda a suprir suas necessidades. Como já citamos, para Clarice "o anonimato é suave como um sonho", no entanto, a realidade dos mass media nos desperta e convoca sempre a fala e a imagem de alguém cuja imagem se deseja explorar.

Silviano Santiago convoca Nietzsche para marcar diferença entre a rapidez do contemporâneo (próprio ao tempo da hegemônica da cultura de massa) e a lentidão do futuro. Nós convocamos a metáfora (aqui, literária) para falar da realidade (aqui, vida literária):

Ao ser contemporâneo de si mesmo, Nietzsche deixa de ser contemporâneo do seu leitor. Nietzsche não está dizendo que escreve para ele mesmo. Diz que escreve a partir de um crédito que ele próprio abriu para si, na crença de que nós, pósteros, iríamos amortizar ou saldar a dívida contraída. [...] O leitor, não o contemporâneo, mas o futuro leitor, está desde a entrada da autobiografia do filósofo, ou da obra do escritor moderno, "implicado" no jogo do crédito autoconcedido. O resgate do investimento não é feito por uma coletividade (de consumidores) no momento imediato ao em que ela estivesse recebendo o produto. Pelo contrário (SANTIAGO, 2004a, p. 120, grifo do autor).

Orr escreve em um caderno azul, adquirido na papelaria de Chang. Sobre ele, coloca palavras e constrói um conto até o momento em que enclausura a personagem principal e não consegue tirá-la de tal situação. Entretanto, também vive um aprisionamento. Na companhia do caderno e na intenção de preenchê-lo, ele se isola em um cômodo e de lá não ouve o telefone, lá não é visto pela esposa que o procura.

Sidney Orr não busca a visibilidade, no entanto precisa dela para se colocar em contato com um mundo que não seja o da ficção, já que a dívida ainda existe e precisa ser paga. Antes mesmo de se ligar ao caderno azul, Sidney havia sido enclausurado na internação. Sua personagem Nick Bowen também se enclausura. Afinal, parece que a figura do escritor não faz questão alguma de se expor. Clarice Lispector, ela também, evitava entrevistas, e só autorizou que a TV Cultura exibisse uma delas, dada a Júlio Lerner, depois que estivesse morta. Não por acaso, 
era desconcertante se desnudar nas páginas do jornal, e havia sempre a necessidade de manter certa parcela de silêncio enquanto outro tanto de si era revelado a cada crônica.

Aspectos relativos à visibilidade e às escolhas do escritor se confrontam com a realidade na medida em que o escritor precisa dos meios de comunicação para a divulgação de sua obra. Como os interesses de um e de outro nem sempre são convergentes, alguém deve ceder e, nesse caso, cabe ao escritor lidar com tal situação. Em situações como essa, ele se torna visível (mesmo à revelia) para que sua obra também seja vista, uma vez que, em uma sociedade em que imagens parecem valer mais do que palavras, não resta alternativa senão a adaptação do escritor ao mercado. Da crônica jornalística ao roteiro cinematográfico.

Este trabalho explora uma realidade que se situa no campo literário, mas que se expande também para outros campos, nos quais há produtores com obras que, para ganharem algum destaque, não têm alternativa senão submeter-se às exigências do mercado midiático. A própria literatura tematiza isso ao falar do drama que é, para um produtor, ter que transformar sua obra para adequá-la a padrões que não satisfazem à sua própria vontade, mas sim à lógica do mercado. Jennifer Egan traz situação semelhante em $A$ visita cruel do tempo, que aqui serve apenas para inspirar trabalhos futuros:

No som construído e sem alma que Bennie e seus colegas de ramo produziam, tudo era efeito. Ele trabalhava de forma incansável e febril para que tudo desse certo, para seguir tendo sucesso, para produzir canções que as pessoas amassem, comprassem e baixassem [...], acima de tudo, para satisfazer à multinacional extratora de petróleo bruto para a qual tinha vendido seu selo cinco anos antes. Mas Bennie sabia que o que estava dando ao mundo era uma merda. Um som cristalino, limpo demais. [...] Um holocausto estético! Bennie sabia que jamais poderia dizer essas coisas em voz alta (2011, p. 27-28).

Não apenas na literatura nos sobram exemplos da realidade que exploramos aqui. Se o escritor tem que se reinventar para garantir a visibilidade de sua obra, também produtores musicais e roteiristas de cinema sofrem com situação semelhante. Em $A$ visita cruel do tempo, o produtor musical Bennie, embora saiba que não oferece ao público uma música de qualidade, não tem alternativa se quiser ter algum retorno financeiro. Apostar no som de que ele gosta poderia sair caro, uma vez que não converge com os interesses da indústria à qual ele pertence. 
Esse cenário apenas alimenta a discussão que iniciamos, de modo que se questione que tipo de produto o mercado deseja oferecer ao público, que, por sua vez, não tem acesso ao que o artista gostaria de oferecer, mas sim ao que a indústria cultural produziu a fim de perpetuar sua lógica capitalista. $\mathrm{O}$ triunfo do mercado implica a derrota do artista, que não pôde sustentar suas ideias e teve que, à revelia, ceder aos imperativos da cultura midiática.

Assim fizeram Clarice Lispector e Sidney Orr, cada um situado na sua realidade ou na sua ficção, no jornal ou no cinema. Buscaram sobreviver ao privilegiar as preferências do mercado em detrimento das suas opiniões pessoais. Agiram com a urgência de quem precisava de dinheiro e não pôde, infelizmente, contrariar a lógica da qual discordavam. Acrescidos a eles, Bennie e tantas outras personagens, cada uma em seu terreno dentro ou fora da ficção, reforçam essa temática e a tarefa de prolongar uma discussão que busque entender (e quem sabe modificar) a exclusão de produtos artísticos na cultura midiática. Afinal, até que ponto será necessário que um artista se desfaça de algumas convicções para adquirir visibilidade? Será que a tendência é uma eterna polarização que segmente a arte em lado oposto ao mercado? Espera-se que não. O meio-termo parece essencial e, nesse sentido, cabe buscar um entrelugar onde possam habitar manifestações artísticas que interessem tanto ao próprio autor quanto à indústria cultural.

Podemos pensar que a crônica configura-se como entrelugar possível. Situada no intervalo entre literatura e jornalismo, ela dialoga com ambas as linguagens e busca poetizar o cotidiano, dar à realidade certo lirismo. Antonio Dimas diz que esse gênero "funciona como oásis lúdico em meio à aridez das notícias secas" (1974, p. 47) e, a partir disso, podemos pensar que o lúdico atrai o público, o leitor que deseja enfim descansar em um ambiente sufocado pela frieza das notícias.

Talvez a crônica seja uma boa aposta. Se, por um lado, Clarice Lispector parece ter se sacrificado, por outro, ela se doou ao público não apenas para fazê-lo conhecer certa parcela da intimidade da autora, mas, sobretudo, para permiti-lo enxergar uma porção poética nos flagrantes de esquina e nos eventos cotidianos. Seus textos preservam assim a possibilidade de gerar encantamento. Nesse sentido, talvez nos caiba ainda acreditar que seja possível, em alguma medida, aproximar as intenções de quem faz a obra aos interesses de quem a divulga. Tarefa nada fácil, mas que pode ter espaço no entrelugar. Sidney Orr teria que empregar ainda mais esforço na tentativa de encontrar tal possibilidade. 
O mais natural, até aqui, tem sido o sacrifício. Quem deseja visibilidade se reinventa ou se submete às exigências do mercado. Cabe a escoIha. Resta-nos esperar que a reinvenção dos escritores encontre espaço, e que eles consigam tornar fértil um terreno ainda raro. Convém apostar no híbrido e acreditar que a criatividade de um escritor o levará aonde ele deve chegar para conseguir sobreviver.

\section{Referências}

AUSTER, P. Noite do oráculo. Tradução José Rubens Siqueira. São Paulo: Companhia das Letras, 2004.

DIMAS, A. Ambiguidade da crônica: literatura ou jornalismo? Littera, Rio de Janeiro: Grifo edições, p. 46-51, 1974.

EGAN, J. A visita cruel do tempo. Tradução Fernanda Abreu. Rio de Janeiro: Intrínseca, 2011.

KELLNER, D. A cultura da mídia. Tradução Ivone Castilho Benedetti. Bauru: EDUSC, 2001.

LISPECTOR, C. Água viva. Rio de Janeiro: Rocco, 1998.

LISPECTOR, C. A descoberta do mundo. Rio de Janeiro: Rocco, 1999.

SÁ, S. de. A reinvenção do escritor: literatura e mass media. Belo Horizonte: Editora UFMG, 2010.

SANTIAGO, S. Literatura e cultura de massa. In: SANTIAGO, S. O cosmopolitismo do pobre: crítica literária e crítica cultural. Belo Horizonte: Editora UFMG, 2004a. p. 106-124.

SANTIAGO, S. Intensidades discursivas. In: SANTIAGO, S. O cosmopolitismo do pobre: crítica literária e crítica cultural. Belo Horizonte: Editora UFMG, 2004b. p. 125-133.

SARLO, B. Ficciones argentinas: 33 ensayos. Buenos Aires: Mardulce, 2012.

Recebido: 10/08/2013

Received: 08/10/2013

Aprovado: 21/10/2013

Approved: 10/21/2013 